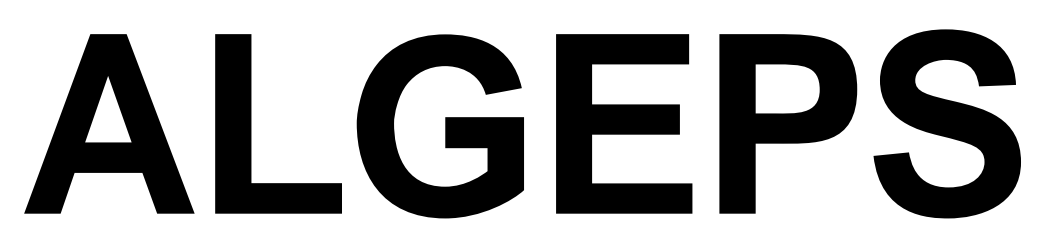

REVISTA DE GEOLOGIA, SÈRIE B $n^{\circ} 609$ - Novembre del 2012

ISSN 1132 - 7014

D.L.B. 28.178 - 92

10 pàgines

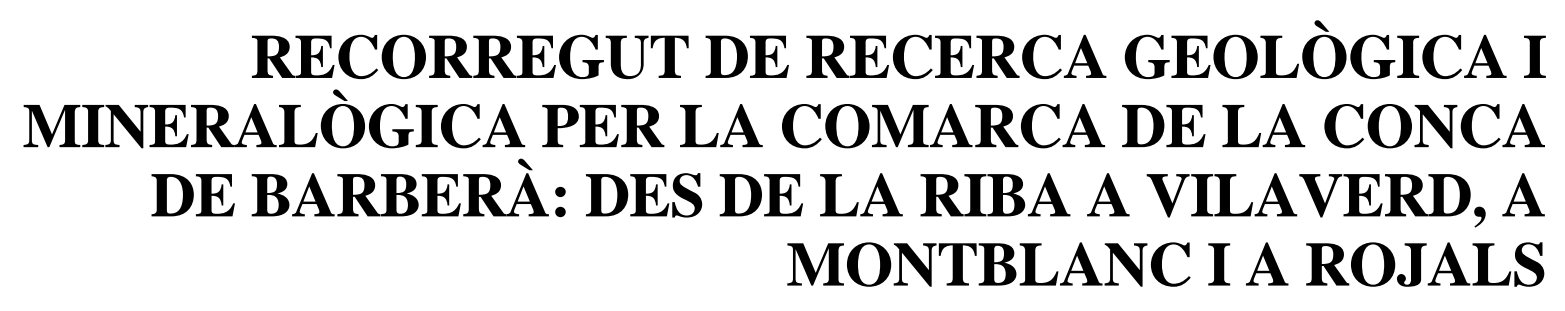

Josep M. Mata-Perelló i Joaquim Sanz Balagué 


\title{
RECORREGUT DE RECERCA GEOLÒGICA I MINERALÒGICA PER LA COMARCA DE LA CONCA DE BARBERÀ: DES DE LA RIBA A VILAVERD, A MONTBLANC I A ROJALS / 5b DE MARÇ DEL 2011
}

\author{
Per Josep M. MATA-PERELLÓ i Joaquim SANZ i BALAGUÉ
}

\section{ADVERTIMENT PREVI}

Com en altres recorreguts de RECERCA GEOLÒGICA I MINERALÒGICA ..., si es disposa del temps suficient, poden efectuar-se passant per totes les parades i filloles. En cas contrari, recomanem prescindir de les anomenades PARADES - CONDICIONALS.

També recomanem de cercar la informació més adient, sobre els trams a recórrer mitjançant camins de terra, o de pista. Aquest és el cas de Rojals a la Mina de la Varidana.

Per d'altra banda, recomanem tenir una cura extrema de la NATURA, evitant qualsevol forma d'agressió sobre ella, o de fer-n'hi un mal ús del que en ofereix la nostra mare Terra.

\section{BREU INTRODUCCIÓ}

En aquesta ocasió, es realitzarà un recorregut geològic i mineralògic a través de diferents indrets de la comarca de la Conca de Barberà, (tot i que el recorregut s'iniciarà a i l'Alt Camp), entre les poblacions de la Riba, Montblanc i Rojals.

Per d'altra banda, el recorregut de l'itinerari s'iniciarà a l'Estret de la Riba de la Serralada Prelitoral Catalana (integrant del Sistema Mediterrani), per on es farà una aturada. Per d'altra banda, en aquest tram, el recorregut passarà de la comarca de l'Alt Camp a la de la Conca de Barberà. Tot seguit, el recorregut penetrarà a la Depressió Geològica de l'Ebre, i més exactament dintre de la seva Depressió Central) pels sectors corresponents a la Cubeta de Vilaverd - Montblanc. La resta dels trams del recorregut, entre Vilaverd i Montblanc, ja es realitzarà exclusivament per la Depressió Geològica de l'Ebre, i per la comarca de la Conca de Barberà. Després, la resta del recorregut entre Montblanc, Rojals i la Mina Atrevida, es tornarà a fer de nou per la Serralada Prelitoral Catalana, sense abandonar en cap moment la comarca.

\section{OBJECTIUS FONAMENTALS D’AQUEST ITINERARI}

Els objectius fonamentals que es pretenen aconseguir en aquest itinerari, es poden concretar en els següents aspectes generals: 
1.- Observació i descripció dels materials paleozoics (quasi sempre del Carbonífer) i dels mesozoics (fonamentalment del Triàsic), que constitueixen la Serralada Prelitoral Catalana, dintre de les comarques de la Conca de Barberà i de l'Alt Camp, a través dels indrets pels quals discorre el recorregut de l'itinerari. Aquests afloraments pertanyen a la vorera oriental de la Taula de Prades (on afloren, per aquests indrets exclusivament els materials mesozoics i els del Carbonífer), situada pels voltants de la Riba i entre Rojals.

2.- Observació i descripció dels materials terciaris (exclusivament del paleogen) de la Depressió Geològica de l'Ebre (i més concretament de la seva Depressió Central), els quals constitueixen part del subsòl de la zona de la comarca de la Conca de Barberà, per la qual discorre el present itinerari. Aquests materials pertanyen en bona part al Grup Pontils (representat aquí entre altres per la Formació Morera de Montsant, la Formació Montblanc i la Formació Valdeperes). Per d'altra banda, també es trobaran materials detrítics, els quals pertanyen a la Formació Sant Miquel de Montclar. Tots aquests materials s'aniran trobant a diferents indrets del recorregut: pels voltants de Montblanc i de la depressió situada entre Vilaverd i la Riba.

3.- Observació de les estructures locals d'aquests materials, al llarg del recorregut de l'itinerari, i de les relacions existents entre les dues unitats geològiques acabades d'esmentar, entre la Depressió Geològica de l'Ebre i el Sistema Mediterrani; i també entre les dues sotsunitats que constitueixen aquest darrer.

4.- Observació de l'Estret de la Riba, per on el Riu Francolí travessa la Serralada Prelitoral Catalana, en abandonar la Depressió Geològica de l'Ebre, pels voltants de la població de la Riba.

5.- Observació de les mineralitzacions filonianes de $\mathrm{Ba}$, situades a la Mina de la Varidana i a la Mina Atrevida (en aquest cas de Ba-Pb-Ag-Ni). Aquestes mineralitzacions es troben a la Serralada Prelitoral Catalana, i encaixen entre els materials paleozoics del Carbonífer de la Taula de Prades.

6.- Observació dels diferents trets relacionats amb la geologia ambiental, que anirem trobant al llarg del recorregut, i en especial dels relacionats amb l'impacte de les vies de comunicació a l’Estret de la Riba.

\section{ANTECEDENTS BIBLIOGRÀFICS}

Pel que fa al recorregut del present itinerari, sols tenim coneixement de l'existència de diferents itineraris nostres, els quals discorren per aquests indrets, tot i que en cap cas ho fan en el sentit d'aquest recorregut. Entre ells farem esment dels següents: MATA-PERELLÓ (1997a, 1997b, 1997c, 1999a, 1999b, 2000 i 2003).

Pel que fa a la descripció de les mineralitzacions situades a les comarques per les quals discorre l'itinerari, farem esment d'un altre treball nostre, relatiu al conjunt de les mineralitzacions catalanes. Es tracta de MATA-PERELLÓ (1991). Tanmateix farem esment de l'important treball de MELGAREJO (1992), corresponent a les mineralitzacions de diverses comarques tarragonines, i entre elles la Conca de Barberà i l'Alt Camp. 
I, finalment, pel que fa a l'estructura geològica de la zona per la qual discorre l'itinerari, farem esment de dos treballs, també referits al conjunt dels Països Catalans. es tracta de GUIMERÀ et altri (1992), així com de RIBA et altri (1976). Per d'altra banda, també ens hem de referir a dues publicacions del mateix any, de l'IGME (1973a i 1973b), relatius a dues fulles del Mapa Geológico de España (a escala 1:50.000).

Tots aquests treballs referenciats, i d'altres, figuren esmentats per ordre alfabètic a l'apartat dedicat a les REFERÈNCIES BIBLIOGRÀFIQUES, al qual ens remetem.

\section{RECORREGUT DE L'ITINERARI}

El recorregut de l'itinerari començarà a l'Estret de la Riba, prop de la població de la Riba, per on ja es farà una aturada. En aquest tram es passarà de la comarca de l'Alt Camp a la de la Conca de Barberà. En aquest trajecte s'haurà circulat per la Serralada Prelitoral Catalana. Després, el recorregut es dirigirà cap a Vilaverd, penetrant a la Depressió Geològica de l'Ebre (Depressió Central), i més concretament a la denominada Depressió de la Riba-Vilaverd. En aquest tram es realitzaran noves aturades. A continuació, el recorregut es dirigirà (ja sempre dintre de la Conca de Barberà, i de la Depressió Geològica de l'Ebre, fins al final del trajecte), tot anant cap a la propera ciutat ducal de Montblanc, la capital de la comarca. Després el recorregut es dirigirà cap a localitat de Rojals, realitzant-se diverses aturades en aquest tram del recorregut. En una d'elles, intentarem arribar fins a les Mines de la Varidana (o de la Bartra), per on efectuarem la darrera aturada.

\section{DESCRIPCIÓ DE L'ITINERARI}

Com de costum, estructurarem el recorregut de l'itinerari en una sèrie de PARADES, que tot seguit anirem veient. En cadascuna d'aquestes aturades farem un breu comentari (geològic o mineralògic, segons s'escaigui). En cada cas indicarem, entre parèntesi, el full topogràfic on es troba l'aturada. Així, cal dir que el recorregut de l'itinerari s'inclourà dintre dels dos següents fulls, del "Mapa Topográfico Nacional", realitzats a l'escala 1:50.000 per l'"Instituto Geografico y Catastral de España": 417 (també dit de l'Espluga de Francolí), 418 (també denominat de Montblanc) i 446 (dit de Valls). A continuació, anirem veient les diverses aturades que composen el recorregut del present itinerari:

PARADA 1. ESTRET DE LA RIBA, (terme municipal de la Riba, comarca de l'Alt Camp). (Full 446).

El recorregut de l'itinerari, cal iniciar-lo en aquest indret, el qual es troba situat a la sortida de la Riba, per la carretera vella que transita per l'esmentat Estret de la Riba, on ara ens trobem situats. En aquest lloc, situat a menys de $1 \mathrm{Km}$ del poble, parem la primera aturada del recorregut d'aquest itinerari.

Cal dir que per la vora del poble ja ens hem trobat els nivells rogencs de gresos i de 
calcolutites del Muschelkalk Mig, sobre els quals es troba situat la Riba. Aquests materials es troben situats a l'esquerra del riu (en sentit descendent), just per on passa la nova carretera. Precisament, com a conseqüència de la plasticitat d'aquests materials, s'han produït freqüents despreniments i esllavissades, per la qual cosa ha calgut construir-hi murs i anclatxes, produintse un fort impacte visual i ambiental. A la sortida de l'esmentat estret, ens hem trobat els trams carbonatats del Muschelkalk Superior, els quals també es fan palesos a la mateixa població, a la riba esquerra del Brugent (en sentit descendent del riu).

Després, poc després de trobar els anteriors materials, apareixen uns nivells de gresos i de calcolutites de color ocre-rogenc, probablement de la Formació Morera de Montsant. (incloent-se aquí dintre del Grup Pontils, essent equivalents laterals de la Formació Carme, present més a llevant). Aquests materials tous, presenten un cabussament cap al NNE, i pertanyen a la Depressió Geològica de l’Ebre (a la seva Depressió Central), i més concretament aquí constitueixen la denominada Cubeta (o Depressió) de Vilaverd - la Riba, la qual queda tancada entre la Serra de Miramar i la Taula de Prades.

Així, situats a l'indret de la parada, es pot veure com a ponent, es troben potents nivells de calcàries (i dolomies), que pertanyen al Muschelkalk Superior, tot formant part de la Taula de Prades. El mateix succeeix cap a llevant, on aquests materials formen part de la Serra de Miramar. Aquests nivells, els d'una banda i de l'altra, van tancant cap al Sud, la Cubeta de Vilaverd, on ara estem situats.

Al lloc on hem d'efectuar la present aturada, a l'entrada septentrional de l'Estret de la Riba, pot veure's el contacte normal, entre els materials carbonatats del Triàsic (tal com hem dit abans, del Muschelkalk Superior), i els calcolutítics i gresencs del Paleogen. Uns i altres, presenten un clar cabussament de component septentrional.

PARADA 2. GUIXERES DE VILAVERD, (terme municipal de Vilaverd, comarca de la Conca de Barberà). (Full 418).

Des de la parada anterior, cal continuar per l'antiga carretera C-240, passant per Vilaverd. Poc després s'arribarà a la nova carretera, per la qual ens caldrà continuar fins arribar a les immediacions del seu Km 34’5.

Als trams inicials d'aquest recorregut, s'han continuat trobant els materials cenozoics anteriorment esmentats (els nivells de gresos i de calcolutites de color ocre-rogenc, que pertanyen probablement de la Formació Morera de Montsant). Tot i que cap a llevant s'entreveuen potents nivells de conglomerats, els quals pertanyen probablement a la Formació de Sant Miquel de Montclar. En canvi, per aquí en aquest trajecte, s'han anat trobant sols els nivells de gresos. Més endavant, haurem començat a trobar uns nivells guixencs, els quals pertanyen a la Formació Valdeperes. Precisament, també cal dir, que aquests materials guixencs han estat explotats prop del lloc on ara som, entre aquest, i la carretera que es dirigeix des de Montblanc cap a Rojals. Aquí, al paratge de les guixeres, es troba abundant GUIX, amb ANHIDRITA, i fins i tot HEMIHEDRITA.

PARADA 3 - CONDICIONAL. CARRETERA C-240, INMEDIACIONS DEL Km 35'9, (terme de Montblanc, comarca de la Conca de Barberà). (Full 418). 
Des de la parada anterior, cal continuar per l'antiga carretera C-240, fins arribar a les immediacions del seu Km 35’9. En arribar-hi, es farà la present aturada, després de recórrer uns 4'5 Km des de l'anterior aturada. Tot i així, es millor parar al $\mathrm{Km}$ 35, per tal d'evitar perills al trànsit. Així, des del Bages, haurem recorregut unes 1'5 Km.

Per d'altra banda, si haguéssim parat prop del Km 35, seria fàcil de veure des d'aquest indret, i mirant cap al fons de l'artesà del Riu Francolí, un aflorament dels guixos de la Formació Valdeperes, que ja hem trobat a la parada anterior.

Més endavant, prop de l'indret de la parada, s'han començat a trobar uns nivells carbonatats, sovint força lutítics, els quals pertanyen a la Formació Bosc dén Borràs. I, precisament, al Km 35'9 en un aflorament d'aquests materials, s'observa una sèrie de plecs, per on discorre encaixonada la carretera.

Prop d'aquest indret, a l'altra banda del Riu Francolí (just a uns 300 m, cap a ponent, d'on ara som), es pot observar una interessant falla, la qual posa en contacte els materials carbonatats de la Formació del Bosc d'en Borràs, amb els ocre-rogencs de la Formació Morera de Montsant, tots ells del Grup Pontils.

Finalment, a llevant d'on ara som, just a la bora de la línia fèrria, es pot veure una interessant demoiselle coiffée, desenvolupada entre els materials quaternaris. Igualment, a la vora de la carretera es pot veure una deformació d'aquests terrenys quaternaris, els quals descriuen un lax sinclinal, el qual es troba entre el Km 34’5 i el 35’8.

\section{PARADA 4 - CONDICIONAL. ERMITA DE SANT JOSEP, (terme municipal de} Montblanc, comarca de la Conca de Barberà). (Full 418).

Després de fer la parada anterior, cal seguir per la carretera C-240, tot anant cap a Montblanc. Poc abans d'arribar-hi es trobarà la carretera nacional $N$-240, per la qual entrarem a la població. En arribar-hi cal anar cap a la propera Ermita de Sant Josep, situada a $1 \mathrm{Km}$, cap al SW. Així, des de la parada anterior, s'haurà fet un recorregut proper als 4’5 $\mathrm{Km}$.

En aquest recorregut s'han anat tallant inicialment els materials carbonatats, esmentats a la parada anterior (els de la Formació Bosc dén Borràs). Prop de Montblanc s'han començat a trobar afloraments de nivells terciaris rogencs, constituïts per calcolutites rogenques que alternen amb nivellets de guixos. Aquests materials pertanyen a la Formació Montblanc, i entre ells es troben concentracions de SILEX (QUARS), d'origen diagenètic, les quals són abundants prop de Montblanc.

També, d'aquest indret, és pot gaudir d'un bon lloc d'observació dels afloraments mesozoics triàsics de la Taula de Prades. Aquesta s'estén a ponent de l'Ermita de Sant Josep, i de Montblanc. També, des d'aquest indret, es poden veure diverses explotacions de calcàries, que aprofiten els nivells d'aquesta composició pertanyents als trams carbonatats del Muschelkalk. 
PARADA 5. CARRETERA TV-7042, CORVA DE PROP DEL Km 8'9, EXPLOTACIONS DE CALCÀRIES, (terme municipal de Montblanc, comarca de la Conca de Barberà). (Full 418).

Des de la parada anterior, cal anar a trobar la carretera TV-7042, la qual es dirigeix cap a Rojalons i Rojals, tot sortint de prop d'on érem a la parada anterior. En arribar prop del Km 8’9, cal fer la present aturada, després d’un recorregut proper als $4 \mathrm{Km}$, des de l'ermita de Sant Josep.

En aquest recorregut, ens hem trobat amb els materials de la Formació Montblanc, cada cop més inclinats, especialment cap els voltants del Km 10 (on hem tallat un paquet de calcàries, explotades cap el Km 10'2), i cap el Collet d'Espadella, on afloren els nivells rogencs de calcolutites.

Poc després del collet es comencen a trobar uns nivells, molt inclinats de calcàries i dolomies del Muschelkalk Superior, que śubiquen dintre de la Serralada Prelitoral Catalana (del Sistema Mediterrani), on hem entrat a l'esmentat collet, deixant enrere de Depressió Geològica de l'Ebre, per on hem estat circulant des de l'inici del recorregut.

Aquestes calcàries són intensament explotades a diferents indrets, i en especial al NW de la corba on ens trobem, veient-se una gran pedrera, la qual provoca un impacte visual bastant marcat.

Per d'altra banda, des d'aquest indret, i mirant cap a l'esmentada pedrera, es pot veure una clara inflexió de les calcàries del Muschelkalk Superior, de forma que passen d'un cabussament sotshoritzontal, al que tenim on ara som, de prop de $70^{\circ}$ cap a llevant. També, des d'aquest indret, es pot veure el contacte de les calcàries acabades d'esmentar, amb els materials terciaris que hem anat trobant des de la sortida de Montblanc.

PARADA 6. CARRETERA TV-7042, CORVA DE PROP DEL Km 7’3, (terme municipal de Montblanc, comarca de la Conca de Barberà). (Full 417).

Des de la parada anterior, cal continuar per la carretera TV-7042, cap a Rojalons i cap a Rojals. En arribar a les immediacions de la corba del $\mathrm{Km} 7^{\prime} 3$, és on ens cal fer la present aturada, després d'un recorregut proper de poc més de 1’5 Km, des de l'anterior.

En tot aquest recorregut, hem continuat trobant els materials carbonatats del Muschelkalk Superior, ja esmentats a la parada anterior. Aquests materials es troben constituïts per nivells de calcàries i de dolomies. Des de l'indret de l'aturada, i mirant cap a l'Est (i cap al $\mathrm{SE}$ ), es pot veure un bon tall dels materials dels diferents trams del Muschelkalk, dibuixant (per altra banda) la inflexió esmentada a la parada anterior.

PARADA 7. CARRETERA TV-7042, COLLET DE PROP DEL Km 6'8, ANTIGA EXPLOTACIÓ DE LUTITES ROJES (I DE GUIXOS?), (terme municipal de Montblanc, comarca de la Conca de Barberà). (Full 417) 
Des de la parada anterior, cal continuar per la carretera TV-7042, cap a Rojalons i cap a Rojals. En arribar a les immediacions del collet del Km 6'8, és on ens cal fer la present aturada, després d'un recorregut proper de poc més de $0 ` 5 \mathrm{Km}$, des de l'anterior.

En un principi, des de la parada anterior, hem continuat trobant els materials anteriorment esmentats del Muschelkalk Superior, constituïts per nivells carbonatats. Prop de l'indret on ara som, hem començat a trobar uns nivells rogencs, fonamentalment de lutites, amb nivellets de guixos, del Muschelkalk Mig.

Per d'altra banda, en aquest indret, hi ha una antiga explotació d'aquests materials, creiem que es dedicava a l'extracció de les lutites roges. Tot i així, també podria haver-se dedicat a l'extracció dels guixos, que en aquest indret són molt abundants.

Des d'aquest indret, i mirant cap a l'Oest, es poden veure ja els afloraments dels nivells carbonatats del Muschelkalk Inferior, per on s'enlaira la carretera formant diverses corbes. Tanmateix, des d'aquest lloc (o millor de uns $100 \mathrm{~m}$, més avall de la carretera), i mirant cap al SW, es poden veure uns interessants congostos del Barranc Estret, dibuixats entre els nivells carbonatats del Muschelkalk Inferior.

\section{PARADA 8. CARRETERA TV-7042, CRUÏLLA CAP A ROJALONS, (Rojalons, terme municipal de Montblanc, comarca de la Conca de Barberà). (Full 417).}

Des de la parada anterior, cal continuar per la carretera TV-7042, cap a Rojalons i cap a Rojals. En arribar a la cruilla del camí que va cap a la primera població esmentada, és on ens cal fer la present aturada, després d'un recorregut proper de poc més de $1^{\prime} 5 \mathrm{Km}$, des de l'anterior.

Tot el recorregut, des de la parada anterior, s'ha efectuat entre els materials carbonatats del Muschelkalk Inferior, els quals es troben constituïts per nivells de calcàries i de dolomies, després de deixar enrere el collet on es trobava la cantera on hem parat abans, i on afloraven els nivells rogencs del Muschelkalk Mig, veient-se clarament com aquest es situen per sota dels nivells carbonatats del Muschelkal Superior, i per sobre dels de l'inferior.

En aquest recorregut, i mirant cap al SW, es poden veure els extraordinaris congostos ja esmentats a la parada anterior, per entre els quals circula el Barranc Estret, i on es troba el Salt de la Variella.

\section{PARADA 9. MINA DE BARITINA DE LA BARTRA, O DE LA VARIDANA, (terme municipal de Rojals, comarca de la Conca de Barberà). (Full 417)}

Des de la parada anterior, cal continuar per la carretera TV-7042 tot anant cap a ponent. Així, aviat s'arribarà a Rojals, en uns $4 \mathrm{Km}$. Després, caldrà continuar per un camí de terra, el qual baixarà cap al Torrent de la Varidiana, des d'on es continuarà cap a la Bartra. En arribar, caldrà anar cap a les Mines de Baritina de la Varidana o de la Bartra, on es farà la present aturada, després de recórrer uns 11 Km més des de Rojals.

En aquest recorregut, en un principi haurem trobat afloraments mesozoics del Triàsic; però més endavant passarem a tallar afloraments dels materials paleozoics, els quals es troben 
quasi exclusivament constituïts per granodiorites.

Precisament, en aquest indret es troben unes interessants mineralitzacions filonianes de baritina, les quals es troben encaixades entre els materials granítics. Entre els minerals presents, cal fer esment de la BARITINA i del QUARS, com a minerals majoritaris, per d'altra banda, també cal fer esment de la presència d'indicis d'ESFALERITA i de GALENA. Finalment, cal dir que el primer dels minerals esmentats (la BARITINA) ha estat motiu d'explotació en diverses ocasions.

\section{EN AQUEST INDRET FINALITZA EL RECORREGUT DE L'ITINERARI}

\section{REFERÈNCIES BIBLIOGRÀFIQUES}

GUIMERÀ, J. et altri (1992).- Geologia (II), Història Natural dels Països Catalans, Vol.2, 547 pag. Enciclopèdia Catalana, S.A. Barcelona.

ITGME (1973a).- Mapa Geológico de España (2 ${ }^{\mathrm{a}}$ Sèrie). Explicación de la Hoja $n^{0} 418$ (Montblanc). Inst. Geol. Min. España. Minist. Indústria. Madrid

ITGME (1973b).- Mapa Geológico de España (2a Sèrie). Explicación de la Hoja nº 446 (Valls). Inst. Geol. Min. España. Minist. Indústria. Madrid

MATA-PERELLÓ, J.M. (1991).- Els Minerals de Catalunya. Arxius de la Secció de Ciències, t. XCIII, 442 pag. Institut d’Estudis Catalans. Barcelona.

MATA-PERELLÓ, J.M. (1997a).- Recorregut de recerca geològica i mineralògica per les comarques de les Garrigues i de la Conca de Barberà. Inèdit, 14 pàg. Manresa

MATA-PERELLÓ, J.M. (1997b).- Recorregut de recerca geològica i mineralògica per les comarques de la Conca de Barberà i de l'Alt Camp: des de Montblanc a Picamoixons, i des de $l^{\prime}$ Illa a Valls. Algeps, sèrie $B, \mathrm{n}^{\circ} 66.13$ pàg. Manresa

MATA-PERELLÓ, J.M. (1997c).- Recorregut de recerca geològica i mineralògica per les comarques de la Conca de Barberà i de l'Alt Camp: des de l'Espluga de Francolí a Picamoixons, i des de l'Illa a Valls. Algeps, sèrie B, n 102. 14 pàg. Manresa

MATA-PERELLÓ, J. M. (1999b).- Recerca Geològica i Mineralògica per la Conca de Barberà: des de Santa Coloma de Queralt a Sarral i des de Montblanc a Rojals. Inèdit, 16 pag. Manresa

MATA-PERELLÓ, J. M. (1999a).- Recorregut de Recerca Geològica i Mineralògica per les comarques de les Garrigues, la Conca de Barberà i de l'Alt Camp: des de Vinaixa a Vimbodí, i des de la Pena a la Riba, Inèdit, 16 pag. Manresa

MATA-PERELLÓ, J.M. (2000).- Recorregut de Recerca Geològica i Mineralògica per les 
comarques de la Conca de Barberà i de l'Alt Camp: des de Valls a Picamoixons i a l'Espluga de Francolí, Inèdit, 14 pag. Manresa

MATA-PERELLÓ, J.M. (2003).- Recorregut de recerca geològica y mineralògica per les comarques de l'Alt Camp i de la Conca de Barberà: Des de la Riba a Rojals i a la Mina Atrevida. Inèdit. 10 pàgines. Manresa

RIBA, O. et altri (1976).- Geografia Física dels Països Catalans, Edit. Ketres, 254 pàgines. Barcelona 